\title{
On Hume’s Defense of Berkeley
}

\author{
Alan Schwerin \\ Department of Philosophy, Monmouth University, West Long Branch, NJ, USA \\ Email: aschweri@monmouth.edu
}

Received 29 May 2015; accepted 31 July 2015; published 3 August 2015

Copyright (C 2015 by author and Scientific Research Publishing Inc. This work is licensed under the Creative Commons Attribution International License (CC BY). http://creativecommons.org/licenses/by/4.0/

\begin{abstract}
In 1739 Hume bequeathed a bold view of the self to the philosophical community that would prove highly influential, but equally controversial. His bundle theory of the self elicited substantial opposition soon after its appearance in the Treatise of Human Nature. Yet Hume makes it clear to his readers that his views on the self rest on respectable foundations: namely, the views of the highly regarded Irish philosopher, George Berkeley. As the author of the Treatise sees it, his account of the self draws on Berkeley's conception of language, especially his views on singular terms. But Hume, as impressed as he is with Berkeley's account of language, deems it necessary to defend this view against possible criticism. In the process Hume modifies Berkeley's views. My paper is a critical investigation of Hume's defense of Berkeley on language and an attempt to highlight the extent to which Hume departs from the views of his Irish colleague.
\end{abstract}

\section{Keywords}

Self, Hume, Berkeley, Bundle Theory, Singular Terms, Language, Linguistic Turn, Substance

This is often Mr Hume's method; but it is neither philosophical nor fair.

(James Beattie, 1770)

\section{Introduction: On the Role of Language in Philosophy}

When Hume publishes his first contribution to philosophical literature in 1739 it has to contend with a number of texts loosely engaged with themes similar to those that interest the philosopher from Ninewells. But one work looms especially large: John Locke’s Essay Concerning Human Understanding (Locke, 1850). There can be little doubt that Locke's account, with its highly influential theory of ideas, is the preeminent text in the science of human nature at the time. As Hume is clearly keen to make his own mark in this field and determined to establish his credentials within the esteemed group of British philosophers dominated by Locke's thought, his first few sections of the Treatise are broadly speaking responses that are directed at Locke's Essay. Hume addresses Locke's views on ideas immediately in his own text, and for good measure very soon thereafter aligns himself 
with a second influential thinker of the period: George Berkeley (Berkeley, 1975).

While Hume is interested in exploring both Locke's and Berkeley's thought on ideas and their relationship to the world, it is Berkeley's views on the importance of language in our attempts to think about the world that strike Hume as especially valuable contributions to the embryonic science of human nature. And when Hume presents Berkeley to his audience the prime focus in his analysis is on a specific argument made famous by the author of A Treatise Concerning the Principles of Human Knowledge: the argument on ideas and terms. As we might expect, much of the section in the Treatise that is on Berkeley is devoted to a consideration of his arguments against abstract ideas. In Hume's view Berkeley's argument on terms and ideas is the centerpiece of this allegedly important and valuable argument against abstract ideas. As Hume sees it, as important as Berkeley's philosophical contributions are on ideas in general, it is his argument on terms and ideas in his broadside against abstract ideas that is especially noteworthy. Hume is intent on elaborating on this argument not only to substantiate his claim that Berkeley is an important thinker in the unfolding science of human nature, but more importantly, he does so to establish the credentials of a conception of language that he himself will later draw on in the articulation and development of his own contributions to the philosophical community.

However, for all its importance to the scientific community and its deserved renown, Berkeley's views on language and more specifically his argument on terms and ideas is not conclusive as far as Hume is concerned. More needs to be done to reinforce it if it is to be put to use by other investigators into issues from the science of human nature. As ingenious as it is, the Irish philosopher's argument on the relationship between language and ideas needs to be supplemented with additional arguments:

As I look upon this to be one of the greatest and most valuable discoveries that has been made of late years in the republic of letters, I shall here endeavour to confirm it by some arguments, which I hope will put it beyond all doubt and controversy. (Treatise 17)

Hume has much to gain from an early critical investigation in the Treatise of the views on ideas that were developed by Locke and Berkeley. Here is a golden opportunity for the neophyte to establish his credibility as an independent researcher dealing with cutting edge theories. But Hume's willingness to draw strong positive attention so soon to Berkeley's views on language, especially the argument on terms and ideas are telling. Hume clearly believes that this philosophy of language is valuable, if not indispensable to the science of human nature that he seeks to be a part of. This fledgling science has to contend with numerous obstacles, any one of which can threaten the integrity and utility of the contributions of its participants. As Hume has advised his fellow researchers engaged in the study of human nature, if the experiments that they conduct are executed judiciously, "we may hope to establish on them a science, which will not be inferior in certainty, and will be much superior in utility to any other of human comprehension." (Treatise ix) Berkeley's insights into language, as I shall argue below, will therefore prove invaluable for Hume, enabling him to provide researchers with a conceptual scheme that will enable them to erect an account of human nature as certain and as useful as any other. So what are these insights? (Hume, 1975, 1978).

\section{Section One: Berkeley's Argument on Ideas, Language and Names}

In his Principles George Berkeley presents an account of the relationship between ideas and language that initially proves to be controversial within the philosophical community, but will later evolve into a highly influential paradigm, in large measure due to the endorsement from Hume and other British empiricists. As Berkeley sees it, there are no abstract ideas. What do exist are particular ideas. As far as the evidence goes, there is no reason to subscribe to the thesis that abstract ideas exist. So why do some philosophers maintain that abstract ideas exist? Berkeley offers an intriguing diagnosis of the motivation that encourages these mistaken philosophers to propose that abstract ideas exist, the lack of evidence notwithstanding (Fieser, 2000).

As he sees it, the adherents of the false view have been misled into subscribing to this position by language. As useful as language is, it unfortunately is often the source of confusion, beguiling the minds of the individuals who use language in various subtle ways. Where the issue of abstract ideas is concerned-an issue that is complex and not easy to resolve-the adherents of the false philosophical view that there are abstract ideas have been deceived by the tools that they are relying on to articulate their thoughts. What is the nature of this deception? Berkeley's response is ingenious:

I come now to consider the source of this prevailing notion, and that seems to me to be language. And 
surely nothing of less extent than reason itself could have been the source of an opinion so universally received. The truth of this appears as from other reasons, so also from the plain confession of the ablest patrons of abstract ideas, who acknowledge that they are made in order to naming; from which it is a clear consequence, that if there had been no such thing as speech or universal signs, there never had been any thought of abstraction. (Berkeley Principles, 73)

The careless application of "speech or universal signs" is the source of the error. More specifically, the names, or terms that the philosophers rely on in their research seduce these investigators into making claims about the existence of non-existent entities. Language is not ontologically neutral, as some might assume: it is fraught with various ontological commitments that influence the reflections of those who rely on it in their challenging philosophical investigations. Had researchers to pay more attention to language and its impact on their reflections, they would be more circumspect with their theorizing. What is called for, most especially, as far as Berkeley is concerned, is caution when using names or terms. The heightened sensitivity to the subtle influence of names would compel philosophers to hesitate before proposing, let alone endorsing and subsequently promoting factually incorrect theses on the existence of questionable entities such as abstract ideas. Unfortunately most philosophers appear to have overlooked the insidious influence of names in their research. For we find that the vast majority of philosophers continue to subscribe to the empirically faulty thesis on the existence of abstract ideas. Might this acclaim not be significant? Perhaps critics of the thesis on the existence of abstract ideas-such as Berkeley-faced with the widespread acceptance of this thesis, ought to pause before attempting to refute it? With so many endorsing the view there surely is something to be said on its behalf? Or could the supporters all be wrong?

For Berkeley the popularity of an opinion is not a reliable indicator of its truth. And even reason does not necessarily guarantee the truth of a view that is widely held. Valid arguments can support false conclusions. A case in point is the claim about abstract ideas. As Berkeley sees it, this received view is false in large measure due to mistaken assumptions about language and names-assumptions that for the most part go unheeded within the philosophical community and in many instances, have yet to be unearthed. A closer empirical investigation of the use of names will reveal the fundamental error behind this mistaken view on abstract ideas - an enquiry that awaits the invaluable contributions of an intrepid philosopher or two. Berkeley sees himself as one of these contributors to what we can call the science of names:

Let us therefore examine the manner wherein words have contributed to the origin of that mistake. First then, 'tis thought that every name hath, or ought to have, one only precise and settled signification, which inclines men to think there are certain abstract, determinate ideas, which constitute the true and only immediate signification of each general name. And that it is by the mediation of these abstract ideas, that a general name comes to signify any particular thing. Whereas, in truth, there is no such thing as one precise and definite signification annexed to any general name, they all signifying indifferently a great number of particular ideas. (Berkeley Principles, 73: his emphasis)

Study the way in which names are used and more will emerge on their nature. Important discoveries await the investigator of names. For one thing, we soon realize that names are not always associated with ideas. There are many occasions where we rely on these "vacuous" names. While the received view is "that language has no other end but the communication our ideas, and that every significant name stands for an idea" there are numerous instances in practical life where a name is used that does not represent an idea. The philosophers who insist that abstract ideas exist have failed to consider these situations. Language is often used for emotional reasons, for instance:

The communicating of ideas marked by words is not the chief and only end of language, as is commonly supposed. There are other ends, as the raising of some passion, the exciting to, or deterring from an action, the putting the mind in some particular disposition... (Principles 74)

Furthermore, familiarity with language over time often conceals the fact that there are no ideas associated with some of the terms that we are relying on. In cases like this we have been conditioned to assume that the symbols we are using are (emotionally) significant and associated with ideas when in fact they are not:

If I mistake not, it will be found that when language is once grown familiar, the hearing of the sounds or 
sight of the characters is oft immediately attended with those passions, which at first were wont to be produced by the intervention of ideas, that are now quite omitted. (Principles 74)

So there is no water-tight relationship between names and their ideas, as even a little experience will make clear to any philosopher who cares to look. From this it follows that the assumption that a name must be associated with an idea, let alone must be associated with only one idea, is patently false. As a matter of fact, there are instances where a name is actually associated with many ideas, but there are other occasions where we find that a name is associated with a single idea. For that matter, there are instances where there is no associated idea accompanying the name. So the assumption that names must always be associated with one and only one idea clearly overlooks the many, many ways in which names are actually used. Names are amorphous entities that can serve a variety of purposes. This fundamental characteristic of names in use entails that it is not always easy to determine whether or not a specific name has an attendant idea, let alone determine which idea—if any-is to be associated with that name: "in truth there is no such thing as one precise and definite signification annexed to any general name.” (Berkeley Principles 73) Hence the insistence that a name be associated with one idea to the exclusion of others-assuming that there even is an idea for the name-is artificial and does not accurately reflect actual linguistic practices. In short, this wide-spread view on names seriously misrepresents the ways in which names can be put to use, as far as Berkeley is concerned:

Tis one thing for to keep a name constantly to the same definition, and another to make it stand everywhere for the same idea: the one is necessary, the other useless and impracticable. (Berkeley Principles, 73: my emphasis)

To illustrate his thoughts on names Berkeley uses the word "triangle". This word, as he sees it, can be successfully associated with numerous ideas no matter how rigorous or complete our definition is of triangles. There will always remain residue ideas left out of consideration when this word is used. For instance, references to the various qualities of the surface that is designated as a triangle are likely to be overlooked with the initial definition of this term. This suffices to establish, as far as Berkeley is concerned, that "there is no one settled idea which limits the signification of the word triangle.” (Berkeley Principles 73)

These are fascinating insights from Berkeley that will later prove influential in the philosophical community. Hume is one, among many, who will draw on these suggestions in his own search for a respectable and useful understanding of human nature. But Hume does not embrace this view of language wholeheartedly. He modifies some aspects of this conception of language and names for reasons that will need to be explored below.

\section{Section Two: Hume's Treatise Response to Berkeley's Account of Language}

Hume opens his presentation of Berkeley's argument against abstract ideas on a somewhat misleading note. From the outset we are led to believe that Hume has unearthed the essence of Berkeley's argument and that as Hume understands it, this argument is about language and its relationship with ideas. The summary statement that he presents to us at the beginning of his analysis of Berkeley soon reveals Hume's views of Berkeley's argument:

A great philosopher [i.e. Berkeley] has disputed the receiv'd opinion in this particular, and has asserted, that all general ideas are nothing but particular ones, annexed to a certain term which gives them a more extensive signification, and makes them recall upon occasion other individuals, which are similar to them. (Treatise 17, my emphasis)

So, as Hume reads Berkeley, the Irish philosopher needs to be applauded for refuting the thesis on abstract ideas by showing that the thesis is the outcome of issues concerning language, namely issues on the multiplicity of possible referents for terms (or names as Berkeley prefers to call them). The discussion that follows this succinct statement is, unfortunately, puzzling. Ostensibly an elaboration and justification of this statement, Section VII of the Treatise turns out to consist of an investigation of the capabilities of the mind and its ability to produce abstract ideas. As Hume's analysis of Berkeley's thesis on abstract ideas and his defense of these views unfold the role of language in Berkeley's argument recedes, to be replaced by an analysis of the capabilities of the mind and a discussion of the nature of ideas and the role of impressions in their formation. Berkeley's core suggestion on the centrality of names where claims about the existence of abstract ideas are concerned is lost in the mix. This is most unfortunate, as Berkeley's argument against abstract ideas does not explicitly explore the 
nature of ideas and the capabilities of the mind, as one might be tempted to infer from a perusal of Hume's presentation. As we have seen, Berkeley's argument against abstract ideas focuses on names and the multiplicity of the relationships that exist between names and ideas. In short, having (correctly) stressed the role of language in Berkeley's argument against abstract ideas in his opening remarks in Section VII of the Treatise, without further explanation Hume proceeds to consider issues tangential to Berkeley's argument. More pointedly, Hume does not place the prime focus on the influence of language in his analysis of Berkeley—as we might expect him to do-but appears to shift to the consideration of a completely different set of issues that happen not to be germane to Berkeley's argument against abstract ideas. While Hume eventually does consider this influence in his analysis of Berkeley's argument against abstract ideas, his references to the insidious influence of language in the section of the Treatise that is devoted to an analysis and defense of Berkeley appear only much later in the section-at practically the half way mark. The references to language and its role in the argument against abstract ideas thus appear almost as an afterthought in Hume's analysis (Bricke, 1980).

Is this a mistake by Hume? And if so, how serious can it be? Why should Hume not go off and consider additional issues when discussing the issue of abstract ideas? In any case, the section is titled, "Of abstract ideas". Is this not what Hume is doing here: namely, exploring the broad issue on these alleged ideas? This rejoinder overlooks a number of important aspects of the analysis in Section VII. I think that the diminution of the role of language in the derivation of abstract ideas is problematic in that it minimizes its importance in Berkeley's argument. As I have attempted to show in the previous section, the argument against abstract ideas is built on Berkeley's views on language and names. This is its foundation. Berkeley's concern with language is central to his argument. So analyses of this argument must give due weight to its importance for Berkeley. To not give it its due, let alone to not emphasize it early on in one's analysis, I suggest, can be regarded as a mistake. That Hume is at fault on this score becomes even more apparent when one takes into account the following remarks made early in the section on the importance of Berkeley's analysis:

As I look upon this to be one of the greatest and most valuable discoveries that has been made of late years in the republic of letters, I shall here endeavour to confirm it by some arguments, which I hope will put it beyond all doubt and controversy. (Treatise 17, my emphasis)

Hume is intent on reinforcing Berkeley's views. But to do so he does something surprising: he changes the focus of the discussion to a different issue. For Hume suddenly shifts to a consideration of the nature of ideas and the capabilities of the mind. That is to say, he removes the spotlight from the issues that Berkeley had originally highlighted in his argument, namely, language and its influence on ideas, and turns the lights on what appear to be a different set of issues. As Hume sees it, Berkeley's account of language and names is not conclusive as it stands, and to reinforce it we (apparently) need to know more about the nature of ideas and their origin. For reasons not made clear in this early section of the Treatise, the valuable suggestions from Berkeley on language are regarded as vulnerable to attack-presumably from the proponents of the discredited doctrine of abstract ideas - and the way to defend them, at least as far as Hume is concerned, is to draw on insights into the ideas that are associated with the (problematic) language that gives rise to abstract ideas. How do we account for what appears to be an indirect way of supporting Berkeley's thesis on abstract ideas—an approach that does not appear to be directly dependent on a philosophy of language and names?

It is not easy to decipher the logic of Hume's defense of Berkeley, unfortunately. Objections against the thesis on the existence of abstract ideas can be raised from a number of quarters, naturally, and while the broad strategy adopted by Hume to fend off some of the potential attacks is relatively straightforward and not that difficult to understand, the details of his tactics prove difficult to follow. Hume's stress on ideas ought not to puzzle us. He has, after-all, devoted the entire opening section of the Treatise to a consideration of Locke's views on ideas, even if he has supplemented this analysis with his own account of impressions. It should not come as a surprise to find Hume continuing along this path, at least initially, when he turns to Berkeley. The analyses in the opening sections of the Treatise clearly have a drift, or momentum that carries Hume along as he moves from issue to issue. So it is understandable that Hume opens his account of Berkeley with an analysis of ideas. But instead of considering ideas in general, or in more global terms, he concentrates his attention on issues concerning a specific set of ideas. The focus is now a little sharper, concerned as it is with abstract ideas. Rather than shift gears to a completely different set of issues-for instance, to consider Berkeley's argument on language and its influence on the postulation of abstract ideas-Hume prefers to continue with the flow that has already been set in motion in the opening sections of the Treatise. He extends his account on the formation of ideas to encompass 
questions on the genesis of the contentious abstract ideas that has attracted the attention of various members of the philosophical community.

For readers familiar with Berkeley—and surely most if not all of Hume's readers in the 1730s would be in this position - this move taken by Hume to defend Berkeley in section VII of the Treatise by initially attending to issues concerning the formation of a specific set of (alleged) ideas, namely abstract ideas, might be seen as unusual. For Berkeley focuses on language in his attack against the claims on the existence of abstract ideas, and one might expect supportive arguments of his attack to follow a similar path. But Hume does not pursue the modus operandi adopted by Berkeley. Here is one of his devotees willing to focus on what appears to be a different set of issues and to offer support from a different, but not unexpected, quarter: namely, an investigation of ideas and impressions. Rather than formulating what could be called a second "linguistic defense", Hume presents us with an "epistemological defense" of Berkeley's thesis against the existence of abstract ideas. The supportive argument from Hume is designed to determine and demonstrate the capabilities of the mind and the nature of its content.

This certainly is a novel way to defend Berkeley. However, as ingenious as Hume's approach is to Berkeley's argument against abstract ideas, it gives rise to a number of potentially fatal difficulties. Hume tries to show that if any abstract idea can form, it will not be the same as the idea purported to exist by the proponents of the thesis of abstract ideas. Adopting the view that an abstract idea is nothing but a general idea - that is to say, an idea that has a general or universal application-Hume argues that the ideas that are able to form in our mind invariably are about particulars or specific individuals:

Abstract ideas are therefore in themselves individual, however they may become general in their representation. The image in the mind is only that of a particular object, tho' the application of it in our reasoning be the same, as if it were universal. (Treatise 20)

While some might be under the impression that they are using terms—or representations, as Hume calls them here- that are associated with ideas that refer to many entities, the ideas that actually do form are about specific referents. The ideas that can form are therefore about particular entities, and are not abstract or general at all.

This procedure to defend Berkeley by drawing on proposals on the formation and nature of ideas is beset with problems that Hume does not appear to be aware of. For it presumes that one can accurately and surgically articulate an epistemological defense of Berkeley views against abstract ideas without any question-begging assumptions. This crucial assumption yields a few serious difficulties, as it turns out, that threaten to undermine Hume's contribution to the debate on the existence of abstract ideas. Unless these underlying issues are dealt with in a satisfactory manner Hume's defense of Berkeley's thesis on abstract ideas will be inadequate, and his argument appear incoherent. Three problems strike me as especially noteworthy.

In the first place, it is important to note that Hume is quite prepared to talk about abstract ideas. And when he does so, he clearly assumes that what he is saying is meaningful or intelligible. When he does talk about these contentious ideas there is absolutely no hesitation at all in his statements. No cautionary expressions accompany his references to these ideas. So the language that he is relying on at least creates the impression that these ideas do actually exist. Take some assertions from him on the issue:

a) 'Tis evident, that in forming most of our general ideas, if not all of them, we abstract from every particular degree of quantity and quality... It may therefore be thought, that here is a plain dilemma, that decides concerning the nature of those abstract ideas, which have afforded so much speculation to philosophers. The abstract idea of a man represents men of all sizes and all qualities... (Treatise 17/18, my emphasis)

b) ...it follows, that there is an equal impossibility of forming an idea, that is not limited and confin'd in both these particulars. Abstract ideas are therefore in themselves individual, however they may become general in their representation. (Treatise 20, my emphasis)

c) This then is the nature of our abstract ideas and general terms; and 'tis after this manner we account for the foregoing paradox, that some ideas are particular in their nature, but general in their representation. (Treatise 22, Hume's emphasis, my underlining)

In each of these instances we are left with the distinct impression that as far as Hume is concerned, there are abstract ideas. They do exist. But little, if anything, is known about them. It remains for the philosopher, who is attempting to investigate them, to determine their nature. Items that are reputed to have a nature need to exist in order for researchers to learn something about them. Put it another way. If the item does not exist, it cannot have a nature. So all this (presumably meaningful) talk from Hume on the nature of abstract ideas encourages us to 
speculate on his views on their existence. If he is excited about, and supportive of Berkeley's arguments against the existence of abstract ideas Hume surely owes it to his readers not to mislead us into thinking that he actually thinks that they do exist.

There is a second problem with the strategy adopted by Hume to defend Berkeley's thesis against the existence of abstract ideas. In his defense Hume draws on his famous thesis on the copy relationship between impressions and ideas to drive home his suggestion that abstract ideas do not exist:

Now since all ideas are deriv'd from impressions, and are nothing but copies and representations of them, whatever is true of the one must be acknowledg'd concerning the other. Ideas and impressions differ only in their strength and vivacity. (Treatise 19)

But Berkeley does not appear to endorse this thesis in his Principles. To the best of my knowledge, this is a thesis that Berkeley never explicitly supports. If I am correct on this score, it seems that Hume is drawing on support for Berkeley that he implicitly assumes will pass muster with the Irish philosopher. But will it? Hume needs to show that Berkeley endorses, or could be persuaded to endorse this important component of his argument. Until Hume does this his attempt to defend Berkeley's thesis with an appeal to the issue of the origin of ideas-with its explicit commitment to impressions-must remain incomplete, if not problematic. To take an extreme option: if Berkeley believes that impressions are unimportant, or perhaps goes further and actually denies that there are impressions-let alone raises questions similar to those from Hume's on the relationships between impressions and ideas-the appeal to impressions in the attempt to support the thesis on abstract ideas is otiose. If the means that Hume relies on to add support to his colleague's thesis is foreign to, or incompatible with that thesis, the defense fails.

There is a third problem with Hume's strategy. This is arguably the most serious shortcoming of the three that I have identified. Hume needs to establish that the thesis that he is defending is actually the thesis presented by and supported by Berkeley. Are they talking about the same entities? More specifically, are Hume's ideas the same as Berkeley's ideas? Hume clearly assumes that there are no differences between the two sets of ideas. But is this assumption well-founded? Unfortunately, nothing is said explicitly by Hume on this question-an omission that threatens to compromise his supportive argument. He needs to show us that the ideas that he is referring to in the Treatise, especially in section VII, are similar to, if not identical with, the ideas that Berkeley writes about. Unfortunately, Hume does not do this. Hume's omission on this crucial point is more urgent when we factor in the following considerations (Laird, 1967).

There is strong evidence to suggest that Berkeley and Hume subscribe to different notions of an idea. Even a cursory investigation into the issue lends support to this proposal. Consider the following line of reasoning in defense of this suggestion. On the one hand, Hume is prepared to refer to impressions as the source of ideas, suggesting that impressions are similar to the ideas that they produce or cause, other than that they are more vivid and stronger. But on the other hand, Berkeley does not talk about impressions at all. Various acts of sensation produce ideas for Berkeley. And acts of sensation are very different to impressions: the former are dynamic processes while the latter are static products, with definite characteristics. So if a product has any bearing on its cause, the ideas that form as a result of Berkeley's sensory processes are likely to be different from the ideas that are caused by Hume's static impressions. Of course, more needs to be said on this important issue and to do so here would be to divert attention from our mission. But my point remains: Hume needs to do the heavy work and establish in detail the specifics of the relationship between his notion of an idea and that espoused by Berkeley. To blithely assume that he is defending a thesis on ideas that Berkeley subscribes to is assume a little too much in this context. All of which suggests that an important question haunts Hume's analysis-a question that must be dealt with if his defense of Berkeley is to count for anything: are the abstract ideas that are referred to in the Treatise the same as the abstract ideas that are mentioned in the Principles?

I have attempted to show that Hume's strategy when defending Berkeley's argument against abstract ideas requires further attention. As novel as his appeal to ideas and their origin might be, there appear to be problems with this line of defense. What now about the tactics relied on by Hume? While Hume's appeal to his views on ideas and impressions might raise questions — some of which I have outlined above—surely his appeal to language and the way it is used in his support for Berkeley is less contentious? Both philosophers make much of linguistic practices in their arguments, so we can be forgiven for at least initially assuming that Hume and Berkeley are on common ground where these issues are concerned. For one thing, the methodology adopted by 
the two thinkers appears to be similar, if not identical. And in their forays into pragmatics the argument that language can mislead investigators in their research into the mind and its content features prominently. So are Hume and Berkeley reaching similar conclusions in their analyses of language and its use? Or are there discrepancies_-possibly serious in nature-between the results acquired from the two approaches? I think that a closer inspection of their analyses will show that there are major differences between the results of their respective investigations into language: deviations that entail that Hume and Berkeley are actually operating with different conceptions of language. These differences manifest themselves most dramatically in the respective treatments meted out by the two philosophers to names. I shall attempt to spell out some of the more important differences in their philosophies of language in the section below by highlighting the differences in their approaches to names. I shall outline Hume's views on names to begin with and follow this with an account of some of the differences between his and Berkeley’s views on names.

\section{Section Three: Are Hume's Views on Language Compatible with Berkeley's?}

While both Hume and Berkeley explicitly acknowledge the invaluable contributions of language in the immature, yet burgeoning science of human nature, they are equally judicious about its potential failings. As Hume sees it, following Berkeley's lead, philosophers must treat language with the greatest respect. Names are particularly important for Berkeley and Hume, and in both the Principles and the Treatise they are singled out for special attention. What invites all this attention is the fact, as they see it, that names can be defective-a shortcoming that could undermine the results from any researcher who is relying on names in their findings. And the most pernicious defect of names for the two thinkers as ambiguity. Preferring to use the word "term" to Berkeley's “name”, a terminological shift not explained in the Treatise, Hume argues that when a word or term is used there are often many similar ideas associated with that symbol. The failure to recognize this possibility, and more importantly, the failure to guard against ambiguity in one's research, constitutes a serious threat to the integrity of that research. This insight encourages Hume to argue that the implicit assumption, let alone the explicit insistence, that there is a tight one-to-one relationship between terms and ideas is false, and not true to practice.

We find the earliest explicit Treatise references to issues on the philosophy of language, and to his views on terms, on page 20 of the Selby-Bigge edition when Hume presents his views on the use of terms and outlines his account on the relationship between terms and ideas. These issues and the overall analysis from Hume appear to be similar to those that Berkeley explored in his argument against abstract ideas, as we have seen. But when we look more closely at Hume's analysis a number of interesting-and dare I say it, disturbing-discrepancies emerge. While there are some features in common in the two accounts of the use of language, especially the insistence that philosophers attend to the ways in which terms are used in practice, Hume's investigation of these diverse linguistic practices introduces elements entirely absent from Berkeley' analysis. Furthermore, it is unfortunately not at all obvious that Berkeley would approve of the (not so subtle) embellishments that Hume introduces into the proceedings with his account of language and terms. Hume is drawing attention to aspects of linguistic practices that are not referred to at all by Berkeley in his account of language. To make matters worse, it remains to be seen whether or not Berkeley could include the elements that Hume makes so much of in his philosophy of language. Let us begin with a consideration of the features of the views on language held in common by the two thinkers and later identify, and explore what strike me as the discrepancies.

When Hume writes in the Treatise on the use of terms and the relationship between terms and ideas he is clearly concerned about the possibility that individuals might be mistaken about what they are doing. This problem will have wide ramifications for others who attempt to use the (confused) results in their own research. The confusion could very well metastasize. Unless one is careful it is possible to use a term inappropriately, and in the process confusing oneself and possibly others. To be a little more specific: individuals need to be aware of the possibility that the term that they are using is not as precise as they might desire it to be. At some stage the term might become ambiguous. While the initial application of the term might have been precise, involving the specific association of the word with a definite particular referent, the subsequent use of the word can introduce a level of ambiguity into the proceedings that could prove to be most unfortunate, invariably giving rise to confusion if not complete error.

Here Hume introduces an interesting distinction. While the ambiguity associated with a term is to be avoided at all costs in philosophy or the sciences in general-because it compromises the search for knowledge and 
truth-there is a place for ambiguity in our lives. With some reluctance he concedes that ambiguity has its place in regular, non-philosophical discourse. In order to "serve the purposes of life" our words and the ideas linked to them often become ambiguous (Treatise 20). What gives rise to the ambiguity are our diverse experiences of a range of similar entities: we observe a number of similar, but not identical entities or situations and tend to minimize their differences:

When we have found a resemblance among several objects, that often occur to us, we apply the same name to all of them, whatever differences we may observe in the degrees of their quantity and quality, and whatever other differences may appear among them. (Treatise 20)

In an ideal world we would have the luxury of using a language that is not ambiguous. But ours is not a perfect world and ambiguity is a necessary evil we need to accept in order to survive and succeed in life. But this unavoidable ambiguity fuels a further complication that is especially pernicious: a set of conditioned mental reflexes form, that if left unchecked, threatens to undermine an individual's ability to reason and think clearly. This is a vital element in Hume's account of names that we need to look at in some detail. In my view this emphasis by Hume on the psychological foundation for the operation of names that we rely on is the most important element of his philosophy of language. Not surprisingly perhaps, this emphasis on our conditioned mental reflexes or custom, as he puts it, also constitutes the distinguishing characteristic between Hume's and Berkeley's conception of names, and by implication, language. As I hope to show below, Berkeley does not stress this component in his account of names nearly to the same extent as Hume does.

\section{Section Four: The Custom That Might Arise}

As Hume sees it, the frequent use of an ambiguous term that is being used to "serve the purposes of life" gives rise to a mind-set that makes it difficult for the user of the term to even notice, let alone possibly correct the mistake. The individual who is using the well-used term is in an especially difficult position because this person finds it practically impossible to disambiguate the ambiguous term that has given rise to the pernicious custom. This difficulty is compounded by the fact that the frequency of application of the term entails that that individual might not even notice the need to disambiguate the term in the first place. To put it succinctly, but somewhat misleadingly: as Hume sees it, language can be the source of malicious deception, over time giving rise to various customs or habits that if left unexamined will lead to the perpetration and the perpetuation of error and confusion on the part of the individuals using the terms from that language. To illustrate his view on the capricious nature of the habits or customs that can form when we carelessly use terms Hume refers to the use of the term "triangle". This example merits closer attention as it is also used by Berkeley in his analysis of names. However, as I shall argue below, in Berkeley's analysis different aspects of our linguistic practices are isolated and emphasized.

The term "triangle" according to Hume can become ambiguous i.e. the set of ideas associated with the term can evolve, according to the needs of the individual using the term. Unfortunately, this alteration is not always apparent. As a result, misleading if not false assertions might be made that presumably compromise the integrity of the individual who is using the term. As he sees it, this problem is fortunately not too serious, arising primarily in (presumably rare) situations where obscure abstract ideas are being alluded to:

...shou'd we mention the word, triangle, and form the idea of a particular equilateral one to correspond to it, and shou'd we afterwards assert, that the three angles of a triangle are equal to each other, the other individuals of a scalenum and isosceles, which we overlook'd at first, immediately crowd in upon us, and make us perceive the falsehood (sp) of this proposition, tho' it be true with relation to that idea, which we had form'd. If the mind suggests not always these ideas upon occasion, it proceeds from some imperfection in its faculties; and such a one as is often the source of false reasoning and sophistry. But this is principally the case with those ideas which are abstruse and compounded. On other occasions the custom is more entire, and 'tis seldom we run into such errors. (Treatise 21, Hume's emphasis, my underlining)

As it happens, suggests Hume, we generally can cope with the ambiguities of our (non-abstract) terms and the resultant insidious customs. The challenges we face are not insurmountable in these cases because the ambiguities and their associated customs are fairly well defined, or as he puts it, "more complete". In short, while a word like "triangle" can be used ambiguously, eventually encompassing ideas not originally thought to be associated 
with it, there are other (presumably less technical) terms in our language that do not give rise to these problems to the same extent. In situations like these we are able to deal successfully with the semantic problems associated with our language.

This is a fairly nuanced account of terms and their ambiguities. Rather than merely dismiss terms as the inevitable source of error and confusion - due to the ambiguities that can arise with the wide range of application of the terms-Hume makes allowance for the distinct possibility that the problems associated with the terms do not entail that the terms are useless. In most cases, implies Hume, we can continue to rely on terms, even ambiguous terms, knowing full well that the terms can be successfully disambiguated. It seems that the problematic terms, that is to say, those that resist treatment, are the abstract terms - presumably those relied on by the philosophers. These abstract terms are thought by (some of) the philosophers to be associated with abstract ideas. But as Hume and Berkeley are at pains to point out, these ideas do not exist. So thinkers who rely on abstract terms invite problems into their analyses: these terms are bound to be misapplied, they become ambiguous in that they become associated with a multitude of ideas—some real and some apparent—and ultimately these terms give rise to logically defective statements that in turn are responsible for "false reasoning and sophistry". (Treatise 21) The logical blemishes endemic to some of the more abstract contributions from the philosophical community can therefore be ascribed to the questionable ambiguous terms and the accompanying malignant customs associated with these misappropriated terms.

It is clear that Hume is concerned with the practicality of the tools that researchers must rely on in their investigations. Ideally, the tools ought to assist the philosophers in their attempts to accomplish the tasks at hand in an efficient manner: the search for reliable and useful knowledge and truth calls for the most efficacious means available. Unfortunately, language proves to be a tool with a checkered history, often proving to be useful, but unfortunately also proving to be a source of confusion and error. The researcher, or philosopher, who is looking into issues that pertain to the science of human nature, for instance, must rely on terms that over time have become ambiguous. And as the issues explored by the philosopher become more abstract, the possibility of error and confusion increase. Allowance must therefore be made for the inescapable fact that the results of some of the research by the philosophers will be less than acceptable. So when many thinkers use a term in different circumstances—-some involving abstract issues, some not—it is most unlikely that that term will become or remain precise. Over time, ambiguity is the inevitable outcome of much philosophical research. Terms, therefore, given their respective histories of ambiguity, must be used with caution, as far as Hume is concerned.

Hume illustrates this important insight into the evolving ambiguity of a term with the term "triangle". Initially, he suggests, there might be a precise definition for the word i.e. a designated idea might be associated with the term;

...shou'd we mention the word, triangle ... the idea of a particular equilateral one to correspond to it [might form] (Treatise 21, my insert)

But this connection between word and idea might change over time, entitling us now to assert that the word "triangle" is to be associated with the idea that "the three angles of a triangle are equal to each other". (Treatise 21) But the associations do not end there, suggests Hume. Before we know it, the word "triangle" can become associated with a completely different set of ideas:

...the other individuals of a scalenum and isosceles, which we overlook'd at first, immediately crowd in upon us ... (Treatise 21)

As the level of ambiguity associated with the term evolves from period to period and from individual to individual - an ambiguity that can be ascribed to a large extent to the evolving linguistic practices of the community drawn to this term-it is vital that the individual who is relying on any given term be aware of the historical precedents that imbue the term with its evolving meanings. At an early stage a term has its fairly well defined or designated idea, but at a later stage the set of ideas presumed to be associated with the term would have morphed into a different set. And this set of associated postulated ideas continues to change. This evolving ambiguity reflects the changes in the priorities of the individuals using the term: broadly put, philosophers, with their emphasis on knowledge and truth might use the term one way, while non-philosophers who are also using, or have used, the term, use it according to their different preferences. Furthermore, within each of these two fundamentally different linguistic communities there are bound to be major discrepancies. The philosophers, for instance, are not a homogenous collection of individuals each one of which is using any given term in a unanimous, un- 
contested manner. Far from it! So the realization that terms are ambiguous—and that this ambiguity alters over time-proves invaluable for the researcher. While the ambiguities associated with any given term might not be readily apparent, with sufficient attention to the various applications of this term, these hidden aspects of the term can be unearthed and appropriate steps taken.

This process clearly calls for a careful methodical approach if the task is to be undertaken successfully. Unless sufficient attention is paid to the evolving ambiguities associated with our terms we are bound to produce theories that contain "false reasoning and sophistry" (Treatise 21). These theories could seriously undermine any efforts to get at the truth, for their ambiguous terms would give rise to confusion and uncertainty. Philosophers must therefore exercise great care with the language that they use. As useful and necessary as it is for articulating the results of the research conducted by scientists, language is beset with semantic difficulties that could seriously compromise its utility to the scientific community. What we need, therefore, intimates Hume is a method to alert the scientists to the possible shortcomings of language. Naturally, any means that can help expose the effluent that hinders clear thinking in general, let alone the errors endemic to the abstruse thinking of the philosophers is to be welcomed. For this reason revelations about the shortcomings of language that are acquired from the study of one of the important constituents of language are to be welcomed. As Hume sees it, George Berkeley has the very tool that is required to assist the philosophers in their scientific endeavors. As we have seen, Berkeley made much of the shortcomings of language in his Principles: an analysis that drew on his understanding of the vagaries endemic to names. In the section "Of abstract ideas" Hume makes it abundantly clear to his audience that as far as he is concerned Berkeley's linguistic thesis on names and ideas provides researchers into philosophical issues with an invaluable insight into the workings and possible shortcomings of language. This is an invaluable tool that researches can put to use in their investigations. For this thesis can be used to help sensitize the minds of the philosophers to the shortcomings of language. As Hume sees it, Berkeley's linguistic thesis enables researchers to better appreciate the shortcoming of language. So the study of names thus proves most helpful, at least for the scientific community, in that it highlights aspects of some of the problems with language that would otherwise remain difficult, if not impossible to detect. And as I have shown above, Berkeley's suggestions inspire Hume in the Treatise to follow a similar course of action. In his analysis of the theory of ideas, especially the consideration of the view on purported abstract ideas, Hume follows Berkeley's lead and also looks closely at names and their various applications. While Hume reaches conclusions similar to those reached by Berkeley, there is at least one significant point of departure in their respective accounts of names that is noteworthy: namely the role of custom in the use of names. Berkeley does mention custom in his account of names, but makes little of this notion. Not so Hume, as we have seen above. What is more, this component of Hume's philosophy of language plays a vital role in his analysis of a crucial problem that he will later wrestle with in his Treatise: namely, the problem of the self. But this is not the place to revisit the role of custom in Hume's arguments on the self. What Hume has done is significant as it stands: namely to prepare the way for future scholars who are interested in the problem of the self. That Hume elicits the assistance of Berkeley in his endeavors to show how important language is in metaphysics when addressing this problem only adds intrigue to his insightful contribution.

\section{References}

Berkeley, G. (1975). Philosophical Works, Including the Works on Vision (M. R. Ayers, Ed.). Totowa, NJ: Rowman and Littlefield.

Bricke, J. (1980). Hume’s Philosophy of Mind. Princeton, NJ: Princeton University Press.

Fieser, J. (Ed.) (2000). Early Responses to Hume's Metaphysical and Epistemological Writings (Volumes Three and Four). Bristol: Thoemmes Press.

Hume, D. (1975). Enquiries Concerning Human Understanding and Concerning the Principles of Morals (L. A. SelbyBigge, \& P. H. Nidditch, Eds.). Oxford: Clarendon Press.

Hume, D. (1978). A Treatise of Human Nature (L. A. Selby-Bigge, \& P. H. Nidditch, Eds.). Oxford: Clarendon Press.

Laird, J. (1967). Hume's Philosophy of Human Nature. London: Archon Books.

Locke, J. (1850). An Essay Concerning Human Understanding. Philadelphia: Troutman and Hayes. 